Background Worldwide, more than five million babies have been born as a result of assisted reproduction technology. Safety aspects are therefore crucial to consider.

Aim By review of the literature to assess if children conceived by assisted reproduction technology are at increased risk of somatic morbidity after the newborn period compared with spontaneously conceived children.

Methods Medline/Pubmed, Embase and The Cochrane Library were searched on May 20, 2013. Studies on assisted reproduction technology and post-neonatal somatic diseases were included in the systematic review. Furthermore, health care contacts, chronic illnesses, surgery, medication and mortality were considered. Cohort and case-control studies were included. To assess the risk of bias in the individual studies, quality of all studies were evaluated independently by two of the authors, using the Newcastle-Ottawa Scale. The PRISMA statement for systematic reviews was followed.

Results Thirty-eight studies, out of 819 identified studies, were included. Results indicate that children conceived by assisted reproduction technology are at increased risk of leukaemia and retinoblastoma, asthma and obstructive bronchitis, genitourinary diseases, and epilepsy or convulsions when compared with spontaneously conceived children. Furthermore, it appears that children conceived by assisted reproduction technology are hospitalised longer per admission, compared with spontaneously conceived children.

Conclusion Children conceived by assisted reproduction technology may be at increased risk of various somatic diseases in childhood compared with spontaneously conceived children.

\section{PS-355 THE DIFFERENT CONTRIBUTIONS OF BODY MASS INDEX AND HEIGHT DURING THE LIFE CYCLE IN PREDICTING ADULT HYPERTENSION}

${ }^{1} \mathrm{MA}$ Barbieri, ${ }^{2} \mathrm{AA}$ Ferraro, ${ }^{1} \mathrm{VC}$ Cardoso, ${ }^{3} \mathrm{C}$ Grandi, ${ }^{1} \mathrm{MRP}$ Gutierrez, ${ }^{4} \mathrm{AAM}$ Silva, ${ }^{5} \mathrm{AD}$ Stein, ${ }^{1} \mathrm{H}$ Bettiol. ${ }^{1}$ Pediatrics, Ribeirão Preto Medical School University of São Paulo, Ribeirão Preto, Brazili, ${ }^{2}$ Pediatrics, São Paulo Medical School University of São Paulo, São Paulo, Brazil; ${ }^{3}$ Neonatal Epidemiology, Ramón Sardá Maternity, Buenos Aires, Argentina; ${ }^{4}$ Public Health, Federal University of Maranhão, São Luís, Brazil; ${ }^{5}$ Public Health, Emory School of Public Health, Atlanta, USA

\subsection{6/archdischild-2014-307384.654}

Background and aims Birthweight and weight gain have been associated with high adult blood pressure (BP). Less well known is the association between height gain across the life cycle and hypertension (HT). The objective of the present study is to assess the independent association of body mass index (BMI) and length at birth and BMI and height gains from birth to childhood, and from childhood to adulthood with adult blood pressure and HT.

Methods A prospective cohort of all living born in Ribeirão Preto, Brazil, was assessed at birth (1978/79), school-age (1987/ $89)$ and adulthood (2002/04). Data on neonatal variables, socioeconomic position and anthropometry of all three moments as well as adult risk factors for HT were present for 1141 subjects. Conditional weight analysis was performed to assess the independent association of BMI and height repeated-in-time measurements on adult HT.

Results After adjustments BMI at birth (inversely: RR $=0.58$; 95\% CI 0.35-0.96), BMI gain in adolescence ( $\mathrm{RR}=3.39 ; 95 \%$ CI 1.87-6.16) and height gain in childhood $(\mathrm{RR}=1.95 ; 95 \%$ CI 1.12-3.38) were associated with adult HT. Adult systolic BP was associated with BMI at birth, BMI and height gains in childhood and adolescence. Diastolic BP was associated with BMI at birth, BMI gain in childhood and adolescence, and with height gain in childhood.

Conclusion Lower BMI at birth, higher height gain between birth and school age and higher BMI gain during the second decade of life were associated with adult HT. BMI and height also predict both systolic and diastolic blood pressure.

Supported CNPq, FAPESP, FAEPA.

\section{PS-356 ASSOCIATION BETWEEN MATERNAL PRE-PREGNANCY BODY MASS INDEX AND SIZE AT BIRTH IN RIBEIRÃO PRETO, SÃO PAULO, BRAZIL}

${ }^{1}$ KSD Trombe, ${ }^{1} \mathrm{H}$ Bettiol, ${ }^{2} \mathrm{RC}$ Cavalli, ${ }^{1} \mathrm{MRP}$ Gutierrez, ${ }^{1} \mathrm{MA}$ Barbieri, ${ }^{3} \mathrm{C}$ Grandi, ${ }^{1}$ VC Cardoso. ${ }^{1}$ Pediatrics, Ribeirão Preto Medical School University of São Paulo, Ribeirão Preto, Brazil; ' ${ }^{2}$ Gynecology and Obstetrics, Ribeirão Preto Medical School University of São Paulo, Ribeirão Preto, Brazil; ${ }^{3}$ Neonatal Epidemiology, Ramón Sardá Maternity, Buenos Aires, Argentina

\subsection{6/archdischild-2014-307384.655}

Background and aims Fetal growth is determined partially by maternal characteristics such as pre-pregnancy weight. Maternal pre-pregnancy anthropometry is useful to estimate birth weight and the risk of various adverse perinatal outcomes. We studied the relationship between pre-pregnancy anthropometry and newborn size. We estimated the risk of low birth weight (LBW, $<2,500 \mathrm{~g}$ ) or high birth weight (HBW, $\geq 4,000 \mathrm{~g}$ ), preterm (PT), small (SGA) or large (LGA) for gestational age in a birth cohort from Ribeirão Preto, Brazil, in 2010, according to maternal prepregnancy body mass index (BMI).

Methods A convenience cohort of 1370 pregnant women living in the city was evaluated between 22-25 weeks of gestation, and their respective newborns. Standardised questionnaires were applied during pregnancy and soon after birth. The dependent variables were LBW/HBW, PT and SGA/LGA. The independent variable was maternal pre-pregnancy $\mathrm{BMI}$, classified as overweight (BMI between 25 and $29.9 \mathrm{~kg} / \mathrm{m}^{2}$ ) and obese (BMI $\geq 30$ $\mathrm{kg} / \mathrm{m}^{2}$ ). Logistic regression models were adjusted for biological, sociodemographic and pregnancy-related variables.

Results A high prevalence of overweight-obesity (39.6\%) was observed and gestational weight gain was above international recommendations, especially among obese mothers. Overweight and obesity before pregnancy, according to pre-pregnancy BMI showed high risk of HBW (RR 2.1, 95\% CI 1.09-3.68 and RR $2.58,95 \%$ CI 1.36-4.91, respectively) and LGA infants (RR 1.96, 95\% CI 1:10-3:49 and 3:47 RR, 95\% CI 1.95-6.16, respectively), but not with LBW, SGA or PT.

Conclusions In this population, frequencies of overweight and obesity were elevated and were independently associated with HBW and LGA.

Supported by FAPESP and FAEPA.

\section{PS-357 FIRST YEAR GROWTH IN RELATION TO PRENATAL EXPOSURE TO ENDOCRINE DISRUPTORS - A DUTCH PROSPECTIVE COHORT STUDY}

${ }^{1} \mathrm{M}$ de Cock, ${ }^{2} \mathrm{MR}$ de Boer, ${ }^{3} \mathrm{M}$ Lamoree, ${ }^{3} \mathrm{~J}$ Legler, ${ }^{1} \mathrm{M}$ van de Bor. ${ }^{1}$ Health and Life Sciences, VU University, Amsterdam, Netherlands; ${ }^{2}$ Health Sciences, VU University, Amsterdam, Netherlands; ${ }^{3}$ Institute for Environmental Studies, VU University, Amsterdam, Netherlands

10.1136/archdischild-2014-307384.656 